\title{
Molecular dynamics study of ternary system $\mathrm{K}+\mathrm{K}^{+q}+\mathrm{O}^{-2 q}$
}

\author{
A.L.Shimkevich, I.Yu.Shimkevich, V.V.Kuzin \\ Institute of Physics and Power Engineering \\ 1 Bondarenko Sq., Obninsk, Kaluga reg., 249020 Russia \\ Received July 9, 1998
}

Results of molecular dynamics (MD) simulation of potassium/oxygen melt, $\mathrm{K}+\mathrm{K}^{+q}+\mathrm{O}^{-2 q}$, at the temperature of $550 \mathrm{~K}$ are presented. MD simulation has been performed for oxygen charge $-2 q=-1,-2$ in the frame of NVT ensemble with only a part of potassium atoms being charged. Evolution of thermodynamic characteristics of the system has been examined up to $t=9.7 \times 10^{-10} \mathrm{~s}$. Voronoi-Delauney theory of division of space into polyhedra has been employed to analyze resulting atomic configurations. Structural and dynamic changes observed, point to the possibility for oxygen to form clusters in alkali metals.

Key words: molecular dynamics, simulation, potassium/oxygen melt, alkali metal, clusters

PACS: $71.15 . D, 74.70 . D d$

\section{Introduction}

Molecular dynamics technique has been used for a more detailed investigation [1] of an impurity influence on the model of ternary liquid potassium/oxygen system, $\mathrm{K}+\mathrm{K}^{+q}+\mathrm{O}^{-2 q}$, with only a part of metal particles being ionized in the melt while keeping the whole system electrically neutral.

\section{Models}

The ternary system, $\mathrm{K}+\mathrm{K}^{+q}+\mathrm{O}^{-2 q}$, has been studied for the temperature of $550 \mathrm{~K}$ in the frame of $N V T$ ensemble for oxygen atomic concentration $8.5 \%$ and potassium ion charge, $q=0.5$ (model I), and $q=1$ (model II). Both models consist of 2000 particles: $N=N_{\mathrm{K}}+N_{\mathrm{K}^{+}}+N_{\mathrm{O}^{-}}$, in a cubic box with periodic boundary conditions. To make the whole system electrically neutral, the number of potassium ions is equal to $N_{\mathrm{K}^{+q}}=2 N_{\mathrm{O}^{-2 q}}: N_{\mathrm{K}}=1490, N_{\mathrm{K}^{+}}=340, N_{\mathrm{O}^{-}}=170$. The volume of the cubic cell, $V=0.9 V_{0}$, where $V_{0}$ is the cube volume corresponding to the 
mass density of liquid potassium, $\rho_{\mathrm{K}}=777 \mathrm{~kg} \mathrm{~m}^{-3}$, and oxide microinclusions mass density, $\rho_{\mathrm{K}_{2} \mathrm{O}}=2320 \mathrm{~kg} \mathrm{~m}^{-3}$, at the given oxygen concentration.

The interaction between neutral potassium atoms $(\mathrm{K}, \mathrm{K})$ and between atoms and cations $\left(\mathrm{K}, \mathrm{K}^{+}\right)$is expressed by Lennard-Jones $n-m$ potential $[2,3]$ :

$$
U(r)=\varepsilon\left[\frac{m}{n-m}\left(\frac{r_{0}}{r}\right)^{n}-\frac{n}{n-m}\left(\frac{r_{0}}{r}\right)^{m}\right], \quad n>m,
$$

with $e=0.0614 \mathrm{eV}, n=6.5, m=4.5, r_{0}=4.7677 \AA$. Born-Mayer's potential without dispersion terms [4] is used for describing $\left(\mathrm{K}^{+}, \mathrm{K}^{+}\right),\left(\mathrm{K}^{+}, \mathrm{O}^{-}\right),\left(\mathrm{O}^{-}, \mathrm{O}^{-}\right)$ and $\left(\mathrm{K}, \mathrm{O}^{-}\right)$interaction:

$$
U_{\alpha \beta}(r)=\frac{Z_{\alpha} Z_{\beta} e^{2}}{r}+C_{\alpha \beta} B\left(1+\frac{Z_{\alpha}}{n_{\alpha}}+\frac{Z_{\beta}}{n_{\beta}}\right) \exp \left[A\left(\sigma_{\alpha}+\sigma_{\beta}-r\right)\right],
$$

with Pauling's coefficients: $C_{\mathrm{K}^{+} \mathrm{K}^{+}}=1.25, C_{\mathrm{K}^{+} \mathrm{O}^{-}}=1$, and $C_{\mathrm{O}^{-} \mathrm{O}^{-}}=0.75$, the ionic sizes: $\sigma_{\mathrm{K}}=1.39 \AA$ and $\sigma_{\mathrm{O}}=1.33 \AA$, the repulsive parameter, $B=0.21098 \mathrm{eV}$ and the softness parameter, $A=3.45 \AA^{-1}$. The number of electrons in the outer shell depends on the ion charge, $\left(n_{\mathrm{K}^{+}}=4.5, n_{\mathrm{O}^{-}}=7\right)$ for model I and $\left(n_{\mathrm{K}^{+}}=n_{\mathrm{O}^{-}}=8\right)$ for model II. The neutral potassium atom interacts with oxygen anion by the same potential at $Z_{\mathrm{K}}=0$ and $n_{\mathrm{K}}=1$.

\section{Computational procedure}

The pair potentials (1) and (2) are tabulated with the step of $0.01 \AA$. The lower and upper potential cut-offs are at $R_{\min }=0.82 \AA$ and $R_{\max }=15 \AA$ for $U_{\mathrm{KK}}, U_{\mathrm{KK}^{+}}$ and $R_{\max }=6 \AA$ for the short-range potential, $U_{\mathrm{KO}^{-}}$. For the long-range potentials, $U_{\mathrm{K}^{+} \mathrm{O}^{-}}, U_{\mathrm{K}^{+} \mathrm{K}^{+}}$, and $U_{\mathrm{O}-\mathrm{O}^{-}}$, the value of $R_{\max }$ is chosen according to the maximum possible region of interaction: for the MD cell edge length, $L=48.604 \AA$, we have $R_{\max }=23 \AA$. The initial configurations are obtained by random placing particles in the cell.

The motion equations were solved using Verlet's algorithm with the time step of $\Delta t=D_{t} \cdot t^{*}$, where $t^{*}=4.074 \cdot 10^{-14} \mathrm{~s}$, the relative time interval, $D_{t}$, was equal $0.005,0.01$, and 0.02 according to the simulation stage. For each particle, its geometrical neighbours within the Verlet's sphere (with the radius, $R_{\text {Verle }}=R_{\max }+1 \AA$ ) were recalculated every 10 time steps. After the system relaxation, the partial radial distribution functions, $g_{\alpha \beta}(r)$, structure factors, $S_{\alpha \beta}(k)$, velocity autocorrelation functions, $\Psi(t)$, frequency spectra, $f_{\alpha \beta}^{n}(\omega)$, and self-diffusion coefficients, $D_{\alpha \beta}$, were calculated at the given time, $t_{i}$. The structure of the system was analysed on the basis of Voronoi-Delaunay's theory for division of space into polyhedra [5].

The MD simulation has been carried out on PC and SUN SPARC workstation using the MDMC code [6].

\section{Results}

Time evolution of the models has been examined up to $9.69 \cdot 10^{-10} \mathrm{~s}$ for model I and $1.0 \times 10^{-10} \mathrm{~s}$ for model II. 
Table 1. Heights, $g_{\max }$, and positions, $r_{\max }[\AA]$ of first peak of $g_{\alpha \beta}$.

\begin{tabular}{|l|rr|rr|rr|rr|}
\hline \multirow{2}{*}{$\alpha \beta$} & \multicolumn{4}{|c|}{ Model I } & \multicolumn{4}{c|}{ Model II } \\
\cline { 2 - 9 } & $t=4.01 \cdot 10^{-11} \mathrm{~s}$ & \multicolumn{2}{|c|}{$t=9.69 \cdot 10^{-10} \mathrm{~s}$} & \multicolumn{2}{c|}{$t=4.01 \cdot 10^{-11} \mathrm{~s}$} & \multicolumn{2}{c|}{$t=1.0 \cdot 10^{-10} \mathrm{~s}$} \\
\cline { 2 - 8 } & $g_{\max }$ & $r_{\max }$ & $g_{\max }$ & $r_{\max }$ & $g_{\max }$ & $r_{\max }$ & $g_{\max }$ & $r_{\max }$ \\
\hline $\mathrm{KK}$ & 2.57 & 4.05 & 2.57 & 4.10 & 2.48 & 4.10 & 2.49 & 4.10 \\
$\mathrm{KK}^{+}$ & 1.73 & 4.10 & 1.77 & 4.15 & 1.53 & 4.15 & 1.53 & 4.10 \\
$\mathrm{~K}^{+} \mathrm{K}^{+}$ & 4.04 & 3.50 & 3.81 & 3.55 & 6.87 & 4.05 & 7.21 & 4.00 \\
$\mathrm{KO}^{-}$ & 1.17 & 6.55 & 1.17 & 6.40 & 1.26 & 5.85 & 1.16 & 4.85 \\
$\mathrm{~K}^{+} \mathrm{O}^{-}$ & 23.06 & 2.80 & 23.20 & 2.80 & 65.50 & 2.30 & 65.00 & 2.30 \\
$\mathrm{O}^{-} \mathrm{O}^{-}$ & 4.17 & 4.80 & 4.37 & 4.70 & 12.40 & 3.70 & 11.50 & 3.70 \\
\hline
\end{tabular}

Table 2. Partial coordination numbers, $Z_{\alpha \beta}$.

\begin{tabular}{|l|rr|rr|rr|rr|}
\hline \multirow{3}{*}{$\alpha \beta$} & \multicolumn{4}{|c|}{ Model I } & \multicolumn{4}{c|}{ Model II } \\
\cline { 2 - 9 } & $t=4.01 \cdot 10^{-11} \mathrm{~s}$ & \multicolumn{1}{|c|}{$t=9.69 \cdot 10^{-10} \mathrm{~s}$} & \multicolumn{2}{|c|}{$t=4.01 \cdot 10^{-11} \mathrm{~s}$} & $t=1.0 \cdot 10^{-10} \mathrm{~s}$ \\
\cline { 2 - 9 } & $Z_{\alpha \beta}$ & $r_{\min }$ & $Z_{\alpha \beta}$ & $r_{\min }$ & $Z_{\alpha \beta}$ & $r_{\min }$ & $Z_{\alpha \beta}$ & $r_{\min }$ \\
\hline $\mathrm{KK}$ & 11.4 & 5.95 & 11.4 & 5.95 & 11.3 & 5.90 & 11.5 & 5.95 \\
$\mathrm{~K}^{+} \mathrm{K}^{+}$ & 5.7 & 6.55 & 5.6 & 6.60 & 5.0 & 5.20 & 5.1 & 5.10 \\
$\mathrm{O}^{-} \mathrm{O}^{-}$ & 3.0 & 6.95 & 2.9 & 7.20 & 2.6 & 5.45 & 2.7 & 5.35 \\
$\mathrm{KK}^{+}$ & 1.8 & 5.70 & 1.8 & 5.70 & 1.5 & 5.20 & 1.6 & 5.55 \\
$\mathrm{~K}^{+} \mathrm{K}$ & 7.9 & 5.70 & 8.0 & 5.70 & 6.8 & 5.20 & 6.8 & 5.55 \\
$\mathrm{O}^{-} \mathrm{K}$ & 3.0 & 8.05 & 2.9 & 7.90 & 1.9 & 7.10 & 1.9 & 7.10 \\
$\mathrm{KO}^{-}$ & 26.3 & 8.05 & 25.0 & 7.90 & 16.7 & 7.10 & 16.5 & 7.10 \\
$\mathrm{O}^{-} \mathrm{K}^{+}$ & 2.0 & 4.10 & 2.1 & 4.50 & 1.9 & 3.25 & 1.9 & 3.20 \\
$\mathrm{~K}^{+} \mathrm{O}^{-}$ & 4.1 & 4.10 & 4.1 & 4.50 & 3.8 & 3.25 & 3.8 & 3.20 \\
\hline
\end{tabular}

Partial radial distribution functions, $g_{\alpha \beta}(r)$, are shown in figure 1 . Their first peak heights and positions are listed in table 1. Partial coordination numbers listed in table 2 were calculated as $Z_{\alpha \beta}=\int_{0}^{r_{\min }} g_{\alpha \beta}(r) \mathrm{d} r$, where $r_{\min }$ is the position of the first minimum of the corresponding $g_{\alpha \beta}(r)$.

As seen from figure 1, the twice increase of a charge changes the form, position, and height of the first peaks and all the coordination numbers $Z_{\alpha \beta}$ are decreased.

The form of functions, $g_{\mathrm{KK}}(r)$ and $g_{\mathrm{KK}^{+}}(r)$, for two models is similar (see figure $1 \mathrm{a}, \mathrm{b})$. The function, $g_{\mathrm{KO}^{-}}(r)$ is different for two models and has comparablesized peaks, $g_{\mathrm{K}^{+} \mathrm{K}^{+}}(r)$ has a high, narrow first peak. Functions, $g_{\mathrm{K}^{+} \mathrm{O}^{-}}(r)$ and $g_{\mathrm{O}^{-} \mathrm{O}^{-}}(r)$, are characterized by the first peak as two subpeaks.

By this is meant that oxygen and potassium ions form hard atomic configurations as linear ramified clusters for oxygen with two potassium trihedra $\left(\mathrm{K}, \mathrm{K}, \mathrm{K}^{+}\right)$and $\left(\mathrm{K}, \mathrm{K}^{+}, \mathrm{K}^{+}\right)$between oxygen ions.

Microdynamic behaviour of the system was examined using the partial velocity autocorrelation function, $\Psi_{\alpha \beta}(t)$ (figure 2), the normalized frequency spectra, $f_{\alpha \beta}^{n}(\epsilon)$, that were defined as Fourier transformation of $\Psi_{\alpha \beta}(t)$ (figure 3), and self-diffusion coefficients, $D_{\alpha \beta}$. 

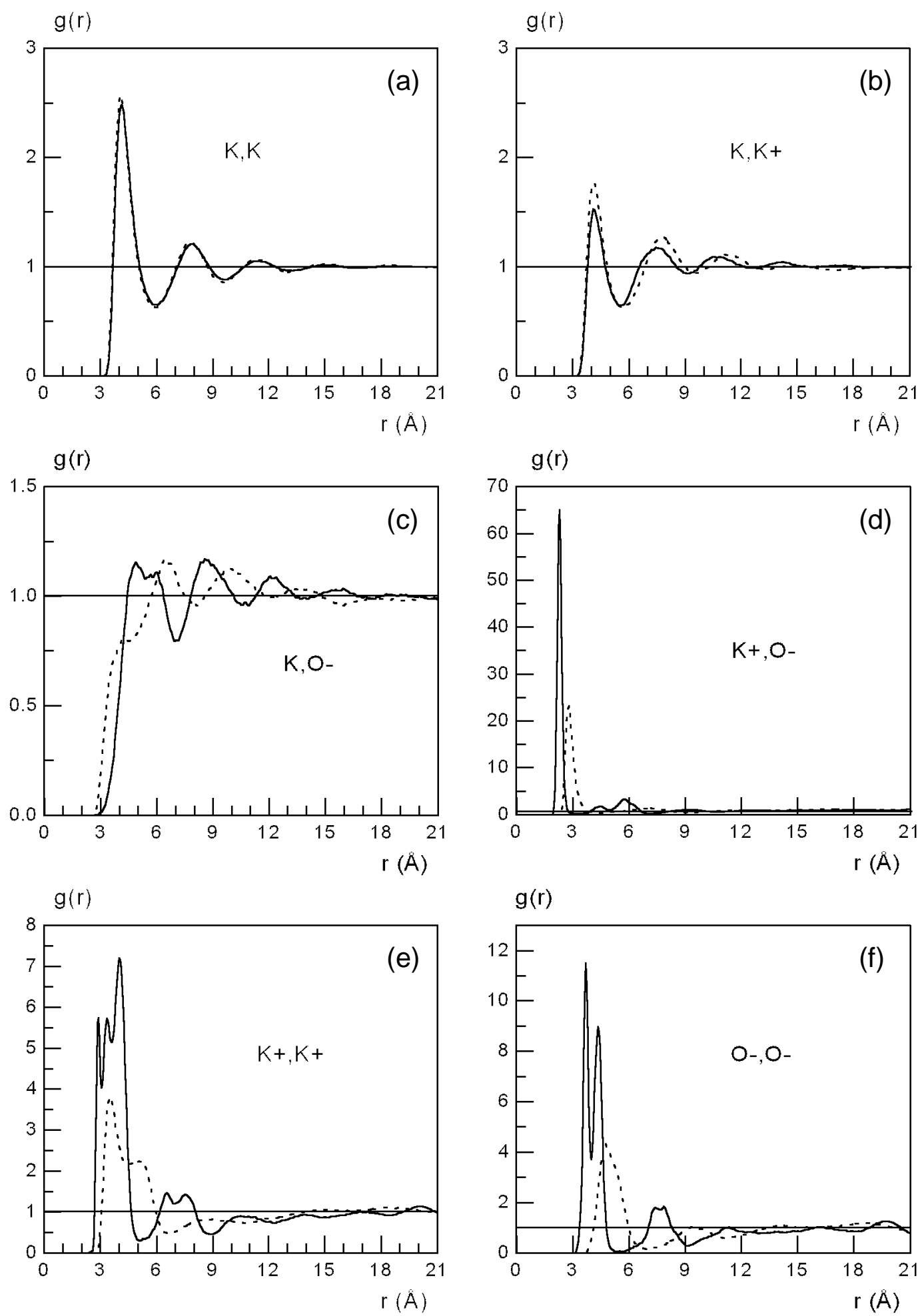

Figure 1. Partial radial distribution functions: (a) $g_{\mathrm{KK}}(r)$, (b) $g_{\mathrm{KK}^{+}}(r)$, (c) $g_{\mathrm{KO}^{-}}(r),(\mathrm{d}) g_{\mathrm{K}^{+} \mathrm{O}^{-}}(r)$, (e) $g_{\mathrm{K}^{+} \mathrm{K}^{+}}(r)$, and (f) $g_{\mathrm{O}^{-} \mathrm{O}^{-}}(r)$. The dotted curves correspond to model I, and the solid curves - to model II. 

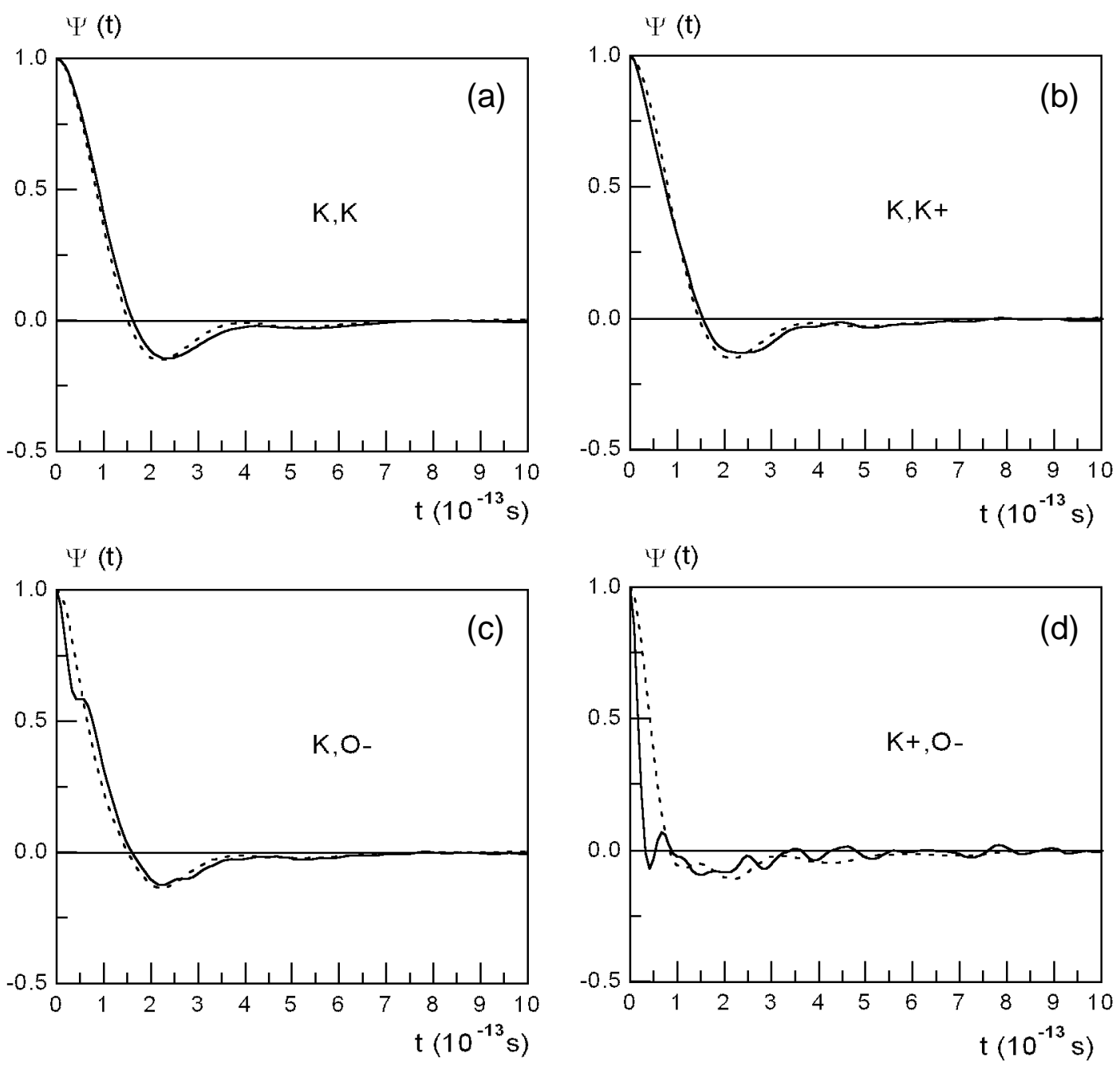

$\Psi^{\prime}(\mathrm{t})$
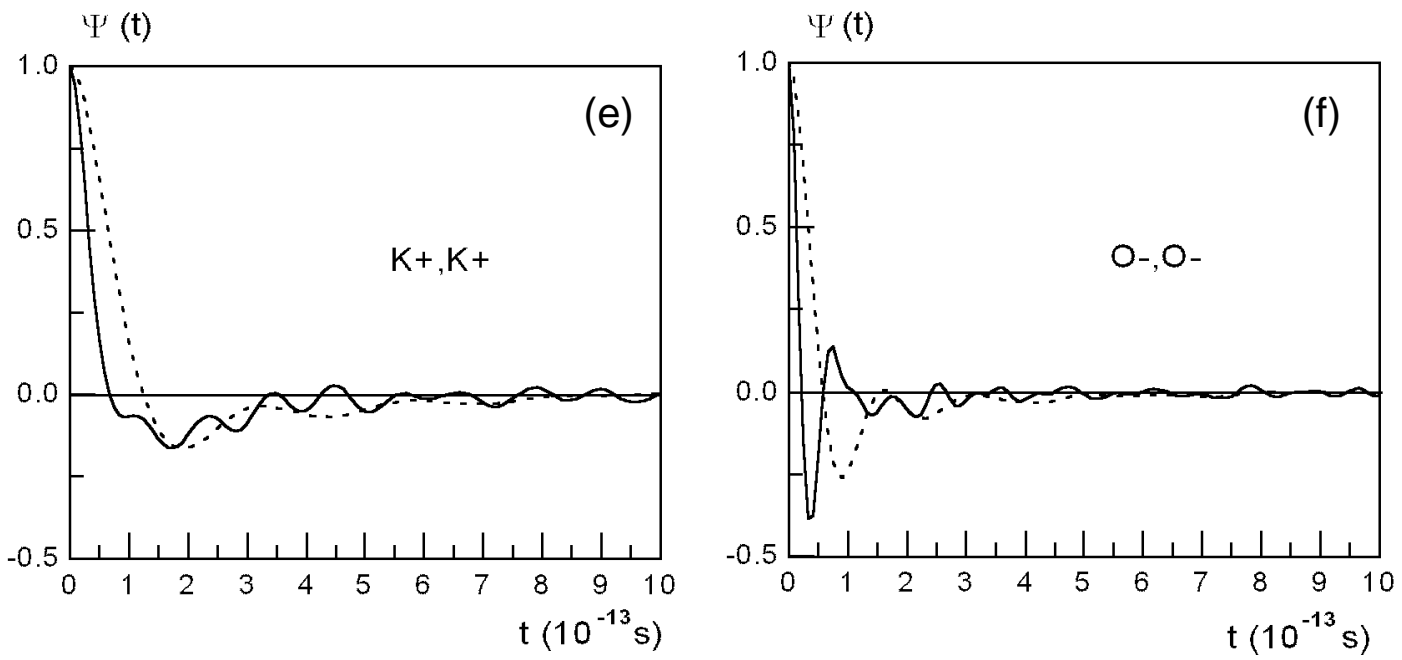

Figure 2. Velocity autocorrelation functions: (a) $\Psi_{\mathrm{KK}}(r)$, (b) $\Psi_{\mathrm{KK}^{+}}(r)$, (c) $\Psi_{\mathrm{KO}^{-}}(r)$, (d) $\Psi_{\mathrm{K}^{+} \mathrm{O}^{-}}(r)$, (e) $\Psi_{\mathrm{K}^{+} \mathrm{K}^{+}}(r)$, and (f) $\Psi_{\mathrm{O}^{-} \mathrm{O}^{-}}(r)$. The dotted curves correspond to model I, and the solid curves - to model II. 

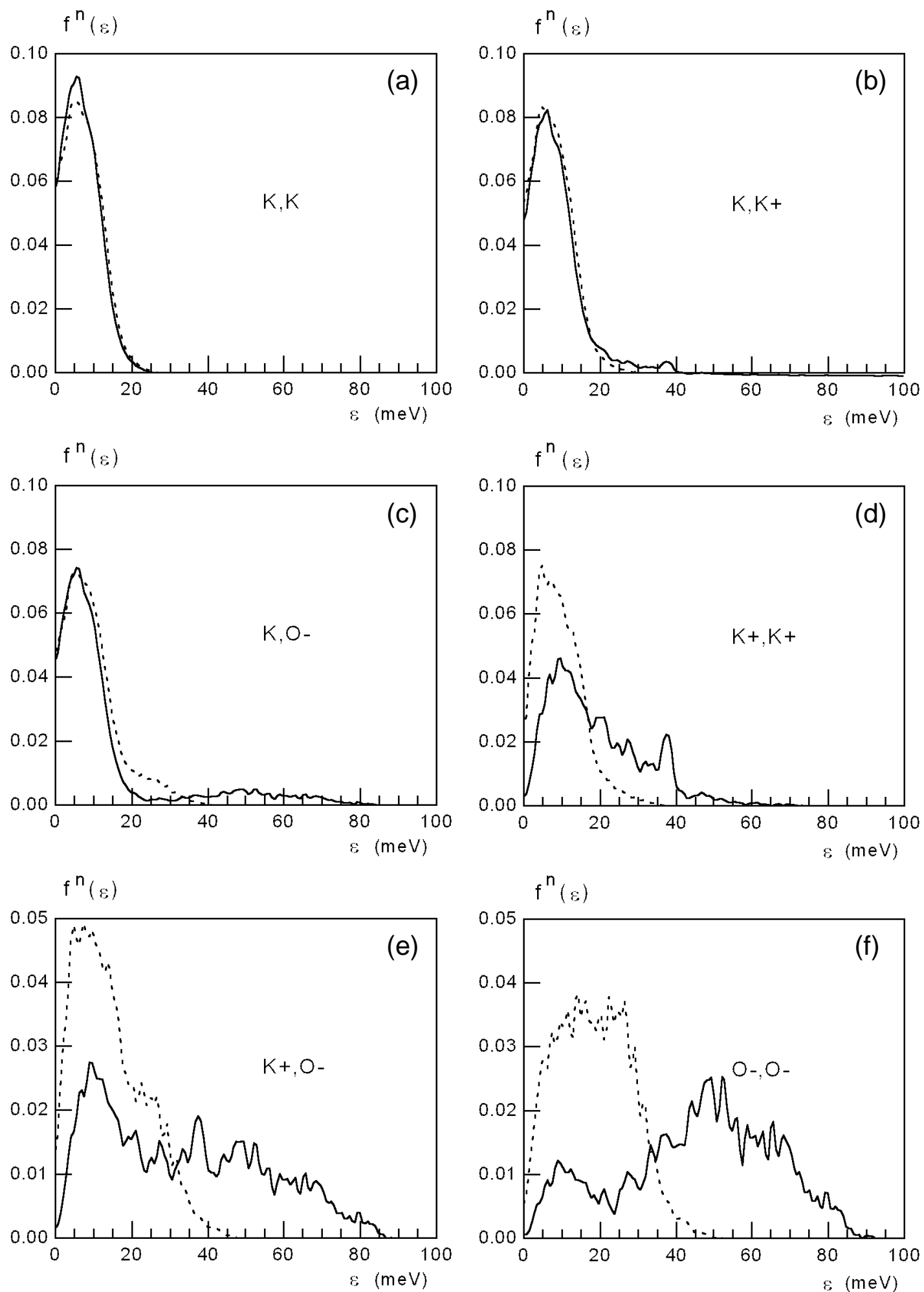

Figure 3. Normalised frequency spectra, (a) $f_{\mathrm{KK}}^{n}(r)$, (b) $f_{\mathrm{KK}^{+}}^{n}(r)$, (c) $f_{\mathrm{KO}^{-}}^{n}(r)$, (d) $f_{\mathrm{K}^{+} \mathrm{K}^{+}}^{n}(r)$, (e) $f_{\mathrm{K}^{+} \mathrm{O}^{-}}^{n}(r)$, and (f) $f_{\mathrm{O}^{-} \mathrm{O}^{-}}^{n}(r)$. The dotted curves correspond to model I, and the solid curves - to model II. 
Table 3. Self-diffusion coefficients, $D_{\alpha \beta}\left[10^{-5} \mathrm{~cm}^{2} \mathrm{~s}^{-1}\right]$.

\begin{tabular}{|l|c|c|c|c|c|}
\hline \multirow{2}{*}{$\alpha \beta$} & \multicolumn{3}{|c|}{ Model I } & \multicolumn{2}{c|}{ Model II } \\
\cline { 2 - 6 } & $4.01 \cdot 10^{-11} \mathrm{~s}$ & $1.00 \cdot 10^{-10} \mathrm{~s}$ & $9.69 \cdot 10^{-10} \mathrm{~s}$ & $4.01 \cdot 10^{-11} \mathrm{~s}$ & $1.0 \cdot 10^{-10} \mathrm{~s}$ \\
\hline $\mathrm{KK}$ & 6.47 & 6.77 & 6.77 & 6.68 & 6.50 \\
$\mathrm{KK}^{+}$ & 5.83 & 6.05 & 6.02 & 5.50 & 5.37 \\
$\mathrm{KO}^{-}$ & 6.05 & 6.28 & 6.26 & 6.05 & 5.87 \\
$\mathrm{~K}^{+} \mathrm{K}^{+}$ & 3.02 & 2.91 & 2.75 & 0.34 & 0.40 \\
$\mathrm{~K}^{+} \mathrm{O}^{-}$ & 2.76 & 2.59 & 2.42 & 0.36 & 0.36 \\
$\mathrm{O}^{-} \mathrm{O}^{-}$ & 2.24 & 1.95 & 1.74 & 0.41 & 0.27 \\
\hline
\end{tabular}

Table 4. Positions of frequency spectrum maxima, $\varepsilon_{\alpha \beta}^{\max }[\mathrm{meV}]$.

\begin{tabular}{|l|c|c|c|c|c|}
\hline \multirow{2}{*}{$\alpha \beta$} & \multicolumn{3}{|c|}{ Model I } & \multicolumn{2}{c|}{ Model II } \\
\cline { 2 - 6 } & $4.01 \cdot 10^{-11} \mathrm{~s}$ & $1.00 \cdot 10^{-10} \mathrm{~s}$ & $9.69 \cdot 10^{-10} \mathrm{~s}$ & $4.01 \cdot 10^{-11} \mathrm{~s}$ & $1.0 \cdot 10^{-10} \mathrm{~s}$ \\
\hline $\mathrm{KK}$ & 4.94 & 5.55 & 5.21 & 3.99 & 5.48 \\
$\mathrm{KK}^{+}$ & 5.14 & 5.55 & 4.33 & 6.16 & 5.68 \\
$\mathrm{KO}^{-}$ & 5.01 & 5.61 & 4.80 & 3.99 & 5.48 \\
$\mathrm{~K}^{+} \mathrm{K}^{+}$ & 5.41 & 5.48 & 4.26 & 7.85 & 8.93 \\
$\mathrm{~K}^{+} \mathrm{O}^{-}$ & 11.17 & 5.55 & 7.04 & 8.05 & 8.86 \\
$\mathrm{O}^{-} \mathrm{O}^{-}$ & 21.72 & 20.98 & 23.07 & 48.30 & 52.20 \\
\hline
\end{tabular}

The calculation of $\Psi_{\alpha \beta}(t)$ corresponds to the simulation over $\Delta T=20 \times 10^{-13} \mathrm{~s}$. The self-diffusion coefficients, $D_{\alpha \beta}$, are listed in table 3 and the positions of the maximum of the normalized frequency spectra in table 4.

As seen from figure $2 \mathrm{a}, \mathrm{b}$, the twofold increase of the oxygen ion charge causes little influence on functions, $\Psi_{\mathrm{KK}}(t)$ and $\Psi_{\mathrm{KK}^{+}}(t)$. The function, $\Psi_{\mathrm{KO}^{-}}(t)$, for $q=1$ differs from the same function at $q=0.5$ by the presence of a 'shoulder' near the moment of $t=0.5 \times 10^{-13} \mathrm{~s}$ (see figure $2 \mathrm{c}$ ). For $q=1$, the ion functions, $\Psi_{\mathrm{K}^{+} \mathrm{K}^{+}}(t)$, $\Psi_{\mathrm{O}^{-} \mathrm{O}^{-}}(t)$, and $\Psi_{\mathrm{K}^{+} \mathrm{O}^{-}}(t)$ transfer rather quickly to a negative value (figure $1 \mathrm{~d}$, e, f). Moreover, these functions oscillate strongly. The large negative region of oxygen velocity also indicates the domination of an isolated oxygen oscillation.

Distinctions of properties between potassium and oxygen for the two models are well seen in frequency spectra, $f_{\alpha \beta}^{n}(\omega)$ (see figure 3 ). The spectra, $f_{\mathrm{KK}}^{n}(\omega), f_{\mathrm{KK}^{+}}^{n}(\omega)$, and $f_{\mathrm{KO}^{-}}^{n}(\omega)$, are similar for two models and have a peak at about $5.5 \mathrm{meV}$. The spectra for model $q=1$ are oscillatory and wide. The oxygen spectrum, $f_{\mathrm{O}^{-} \mathrm{O}^{-}}^{n}(\omega)$, for charge $q=0.5$ has the high and wide peak at $20-30 \mathrm{meV}$ (the dominating frequency of atomic vibration) and two different peaks at $\sim 10 \mathrm{meV}$ and $\sim 50 \mathrm{meV}$ for $q=1$ that may be interpreted as longitudinal and transverse modes of oxygen ramified chains.

The additional analysis of potassium/oxygen mixture structure by means of the statistical geometry confirms the formation of oxygen clusters (see figure 4). The length of branches increases with the oxygen charge increasing. 

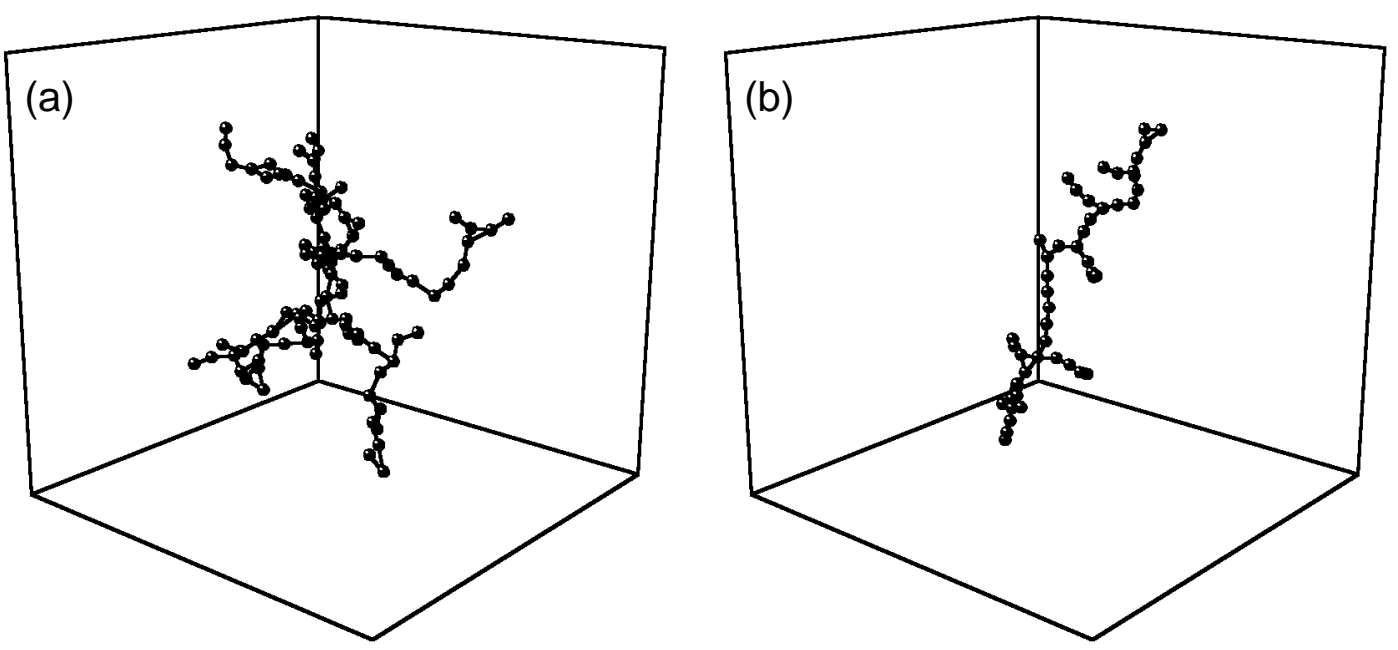

Figure 4. The greatest clusters, composed of oxygen ions. Two oxygen ions are considered as linked if they have at least 3 common neighbours. Shown in the figure are the oxygen clusters of maximum size for (a) model $\mathrm{I}, t=9.7 \cdot 10^{-10} \mathrm{~s}$, and (b) model II, $t=1.0 \cdot 10^{-10} \mathrm{~s}$. The edge length of the bounding cube in the figures, $L^{*}=100 \AA$.

\section{Summary}

The observed structural and dynamic changes of liquid potassium/oxygen system are caused by the process of impurity behaviour and by an atomic clusterization in liquid alkaline metals.

\section{References}

1. Shimkevich I.Yu., Kuzin V.V., Shimkevich A.L. Molecular-Dynamics simulation of liquid potassium with oxygen. Preprint of the Institute of Physics and Power Engineering, IPPE-2567, 1996, 17 p. (In Russian).

2. Shu Zhen, Davies G.J. Calculation of the Lennard-Jones $n$ - $m$ potential energy parameters for metals. // Phys. Stat. Sol. (A), 1983, vol. 78, p. 595-605.

3. Shimkevich I.Yu., Novikov A.G., Savostin V.V., Shimkevich A.L. Structure and dynamic properties of MD-model of liquid potassium. Preprint of the Institute of Physics and Power Engineering, IPPE-2437, 1995. (In Russian).

4. Tissen J.T.W.M., Janssen G.J.M. Molecular-dynamics simulation of molten alkali carbonates. // Molecular Physics, 1990, vol. 71, No. 2, p. 413.

5. Kuzin V.V., Morozov V.A., Shimkevich A.L., Shimkevich I.Yu. On the structure of molecular-dynamics model of liquid potassium. Preprint of the Institute of Physics and Power Engineering, IPPE-2415, 1994, 18 p. (In Russian).

6. Shimkevich I.Yu., Shimkevich A.L. MDMC (Molecular-Dynamics and Monte-Carlo) software to study crystalline and irregular systems. Preprint of the Institute of Physics and Power Engineering, IPPE-2524, 1996, 25 p. (In Russian). 


\title{
Дослідження потрійної системи $\mathrm{K}+\mathrm{K}^{+q}+\mathrm{O}^{-2 q}$ методом молекулярної динаміки
}

\author{
А.Л.Шимкевич, І.Ю.Шимкевич, В.В.Кузін \\ Фізико-Енергетичний Інститут \\ Росія, Калужська обл., 249020 Обнінськ, пл. Бондаренка, 1 \\ Отримано 9 липня 1998 р.
}

Подані результати моделювання методом молекулярної динаміки (МД) розплаву калій/кисень $\mathrm{K}+\mathrm{K}^{+q}+\mathrm{O}^{-2 q}$ при температурі $550 \mathrm{~K}$. МД моделювання виконувались у $N V T$ ансамблі для заряду кисню $-2 q=-1,-2$, причому лише частина атомів калію була зарядженою. Еволюція термодинамічних характеристик системи аналізувалась 3 точністю до $t=9.7 \times 10^{-10} \mathrm{~s}$. Для аналізу отримання атомних конфігурацій застосовувалась теорія поділу простору на многогранники Вороного-Делоні. Виявлені структурні та динамічні зміни вказують на можливість формування кисневих кластерів у лужних металах.

Ключові слова: молекулярна динаміка, моделювання, розплав калій/кисень, лужні метали, кластери

PACS: $71.15 . D, 74.70 . D d$ 
